\title{
SUITABILITY OF RICE HUSK ASH MOULD ADDITIVE FOR THIN WALL DUCTILE IRON GRAPHITE CHARACTERISTICS
}

\author{
E. F. Ochulor ${ }^{1,}{ }^{*}$, M. O. H. Amuda ${ }^{2}$, S. O. Adeosun ${ }^{3}$ and S. A. Balogun 4 \\ 1,2,3, DEPT. OF METALluRgiCAL AND MATERIALS EnGINEERING, UniV. OF LAGOS, AKOKA, LAGOS STATE, NIGERIA

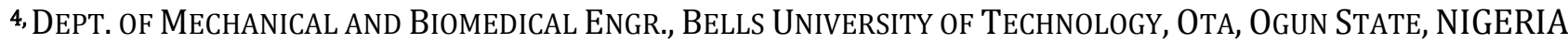 \\ E-mail addresses:1 fochulor@yahoo.com, 2 mamuda@unilag.edu.ng, 3 samsonoluropo@yahoo.com \\ 4sanmbo2003@yahoo.co.uk
}

\begin{abstract}
Thin wall ductile iron (TWDI) components are used in automobile and related sectors owing to weight savings without sacrificing functional properties. However, its application is hampered by low ductility owing to carbide precipitation and poor nodule characteristics in as-cast structure. In this study, mould thermal characteristics are adjusted using rice husk ash (RHA). Green sand was blended with 1-6 wt. \% RHA to produce moulds for casting of 4 mm TWDIs, samples obtained were subjected to microstructural (Optical, SEM and EDS), hardness and strength analyzes. Elemental composition of carbide precipitates showed iron and carbon. Nodularity ratings $>90 \%$, nodule count $>1000$ nodules $/ \mathrm{mm}^{2}$ and strength of $596 \mathrm{MPa}$ were observed in samples cast in $4 \mathrm{wt}$. \% RHA sand mix. Ductility of 6.1 occurred in $6 \mathrm{wt}$ \% RHA/sand mix. The sand-RHA mix offers cooling rate control, reduction of precipitation of deleterious carbides and superior graphite characteristics in $4 \mathrm{~mm}$ TWDI castings.
\end{abstract}

Keywords: cooling rate, carbide precipitate, nodules, properties, sand

\section{INTRODUCTION}

The potentials of Thin Wall Ductile Iron (TWDI) are currently being utilized in lightweight automotive parts for energy saving requirements. Many automotive components are produced using ductile iron (DI) owing to its high strength and good ductility, good cast-ability, machinability and fatigue strength [1]. The cooling rate of castings is primarily dependent on casting size, pouring temperature and mould material thermophysical properties. TWDIs are $2-5 \mathrm{~mm}$ section DIs [2]. The common feature of all DIs is the near spherical shape of graphite nodules, which act as crack-arresters and consequently make the iron more ductile. With a high percentage of nodules present in the structure, the mechanical properties are determined by the ductile iron matrix [3]. Due to section size reduction, the production of thin wall sand casts presents unique challenges. The high surface area to volume ratio in the thin sections results in very high solidification rates and can cause mis-runs or other defects, undesirable microstructures and poor mechanical properties.

To date, most methods used to produce thin wall castings focused on metal chemistry, inoculation and gating practice. Few practical methods have been employed to retard cooling and reduction of solidification rates in conventional sand moulds. However, improvement in heat capacity and thermal conductivity of the mould and core materials may reduce cast wall thickness more than other factors combined. This could be achieved through density and thermal properties adjustment of individual mould and core components or inserts. The mould/core package can be engineered to give optimum flow and cooling characteristics [4]. In the solidification process, the change of liquid to solid metal after pouring into the mould is the defining event in the life cycle of casting [5]. The time involved in this transition may be as short as seconds or as long as hours depending upon the casting process, the size of cast, the chemical composition of the metal being cast, the manner of solidification and the subsequent solid state treatment, which determines the ultimate microstructure and properties (mechanical and physical) of the cast [6]. The heat exchange in the metal-mould system is essential to the kinetics of cooling and solidification of a cast, especially in TWDI castings, which start to solidify during mould filling and determines the cooling rate [7]. In the study of [8], the effects of RHA and aluminum 
dross (AlDr) as additives to silica sand on its moulding and thermal properties were investigated, the researchers observed a progressive reduction in thermal conductivity with increased weight percent RHA additive, 30\% reduction in thermal conductivity was observed at 6 wt. \% RHA. The goal under this condition is to control the solidification event so that the desired microstructure (superior graphite characteristics i.e. nodularity and nodule count, matrix type) for enhanced mechanical properties in the final product is obtained. The authors in [9] investigated the effect of moulding sand- aluminium dross mix on the microstructure and mechanical properties of as-cast thin wall ductile iron (TWDI) and concluded that microstructure, hardness and tensile strength of TWDI samples were impaired, while ductility of these samples were enhanced when compared to the control samples cast without the aluminium dross mould additive.

The main constituents of TDWI casting matrix are ferrite, pearlite and carbides, if any. Their actual ratio is highly dependent on the processing parameters namely cooling rate, liquid treatment, chemical composition, pouring temperature, etc. The mould thermo-physical property is a crucial variable that affects the chilling tendency of TWDI castings [10]. Moulds with high thermal conductivity remove heat faster from the molten metal, causing it to solidify early and stop flowing.

In this study, green sands moulds were blended with 16 wt. \% rice husk ash (RHA), the resulting sand mix were subjected to thermal conductivity test to determine the extent of thermal insulation and consequently the microstructure and mechanical properties of $4 \mathrm{~mm}$ TWDIs cast using blends of moulding media were evaluated.

\section{MATERIALS AND METHODS}

\subsection{Materials Preparation}

Fifty (50) $\mathrm{kg}$ of rice husk, a by-product of rice production in rice mills is obtained from Ifo in Ogun
State, Nigeria. Combustion of this agro-waste was carried out in a Gemco CFR 90337 electric furnace at $700^{\circ} \mathrm{C}$ in a controlled atmosphere for 10 hours at Federal Institute of Industrial Research Oshodi, Lagos. After combustion and cooling, sieve analysis was conducted and only RHA particles between 250-300 $\mu \mathrm{m}$ were used for the moulding sand preparation. This was done to ensure the use of similar particle size to that of silica moulding sand, as good surface finish is required in TWDI casts. A control composition of the green moulding sand is used to cast the $4 \mathrm{~mm}$ plates to compare with that cast using sand-RHA mixes. The sand constituents are mixed for 5 minutes using a Rhino model IRM-500 sand mixer located at Nigerian Foundries Ilupeju, Lagos. Using this standard composition of moulding sand, six different mixes of the moulds were prepared by adding varying weight percentages of RHA to the moulding sand. Chemical analysis of RHA used and the control composition of green moulding sand are shown in Tables 1 and 2 respectively. Table 3 shows six different mould compositions prepared by adding varying weight percentages of RHA to control moulding sand.

The choice of weight percentages of RHA used is based on a preliminary trial test conducted on $600 \mathrm{~g}$ of moulding sand. The test determined the upper limit (6 wt. \%) of RHA to be used as higher weight percent resulted in decline of moulding sand properties. Moulding sand property test was conducted on moulding sand-RHA mixes to ensure that these properties are adequate and conform to established standard foundry practice.

The thermal conductivity of the sand mixes was determined using the KD 2 Pro Thermal Conductivity Meter, during moulding after the pattern was removed, before coupling and the temperature read was $28.83^{\circ} \mathrm{C}$. The TR-1 and SH-1 sensors were used to measure thermal conductivity and thermal diffusivity respectively. The samples were cast using standard casting procedure after melting charge materials. Charge material composition is shown in Table 4.

Table 1: Chemical Composition of Rice husk ash [8]

\begin{tabular}{llllllllll}
\hline Constituent & $\mathrm{SiO}_{2}$ & $\mathrm{Al}_{2} \mathrm{O}_{3}$ & $\mathrm{TiO}_{2}$ & $\mathrm{Fe}_{2} \mathrm{O}_{3}$ & $\mathrm{CaO}$ & $\mathrm{MgO}$ & $\mathrm{K}_{2} \mathrm{O}$ & $\mathrm{Na}_{2} \mathrm{O}$ & LOI \\
\hline Wt. \% in RHA & 93.15 & 0.21 & 0 & 0.21 & 0.41 & 0.45 & 3.21 & 0 & 2.36 \\
\hline
\end{tabular}

Table 2: Control Composition of the green moulding sand [8]

\begin{tabular}{cccccc}
\hline Materials & Silica Sand & Bentonite & Starch & Coal Dust & Water \\
\hline Comp (wt. \%) & 96.4 & 2.2 & 0.8 & 0.2 & 0.4 \\
\hline
\end{tabular}

Table 3: Sand Specimen with wt. \% of RHA [8]

\begin{tabular}{llllllll}
\hline Specimen & RH & RH1 & RH2 & RH3 & RH4 & RH5 & RH6 \\
\hline RHA (wt. \%) & 0 & 1 & 2 & 3 & 4 & 5 & 6 \\
\hline
\end{tabular}


Table 4: Chemical composition of charge materials

\begin{tabular}{llllll}
\hline Charge & wt. \% (Kg) & Charge (\%) & C (\%) & Si (\%) & Mn (\%) \\
\hline Mild Steel & 300 & 60 & 0.1 & 0.1 & 0.2 \\
Ductile Iron Returns & 80 & 34 & 0.1 & 0.1 & 0.2 \\
Ferro Silicon & 7 & 1.4 & 0.00 & 70 & 0.00 \\
Graphite & 23 & 4.6 & 70 & 0.00 & 0.00 \\
\hline
\end{tabular}

\subsection{Microstructural Analysis}

Samples for microstructural analysis were cut, ground and polished according to ASTM Standard E3 for metallographic analysis. The prepared samples were viewed in their unetched and etched (using $2 \%$ nital solution) conditions using both a CETI Optical Metallurgical Microscope Model No. 0703552 at magnification of X100 located at the Metallurgical Laboratory, University of Lagos, Akoka, Lagos and a Scanning Electron Microscope at magnification of X2000, equipped with an energy dispersive spectroscopy (EDS) system located at the Mechanical Engineering Laboratory, Covenant University, Ota, Ogun State. Microstructural analysis (nodularity as in Equation 1, nodule count and matrix type) was carried out using manual procedure as stated in ASTM A247 and E407 standard procedures. The latter technique (SEM) was used to enable a detailed observation of the matrix microstructure resulting from subsequent eutectoid reaction.

Nodularity \%

$=\frac{\text { area (number) of acceptable particles }}{\text { area (number) of all particles }} \times 100$

Nodule Count (graphite nodules $/ \mathrm{mm}^{2}$ ) is the quantity of nodules per square millimeter on a polished surface examined at X100 magnification.

\subsection{Hardness Test}

Brinell hardness test was done using a $10 / 3000 \mathrm{~kg}$ indenter ball on tester model Foundrax /B.H.D/ 1003402 at the Nigerian Foundries Limited Ilupeju, Lagos in line with ASTM E10 standard.

\subsection{Tensile Test}

Tensile property test was carried out as in ASTM E8 standard using a Universal Instron 3369 Tensometer, system identification number: 3369K1781, located at the Centre For Energy Development, Obafemi Awolowo University, Ile-Ife, Osun State.

Regression analysis of plots was done to determine relationships among the variables under investigation with equations and regression coefficients also predicted.

\section{RESULTS AND DISCUSSION}

\section{1: Effect of RHA addition on Moulding Sand Thermal Characteristics}

Spectrometric analysis of TWDI samples is shown in Table 5. Figure 1 shows variation of thermal conductivity of the sand mixes with wt. \% RHA additive. The thermal properties decline with increase in wt. \% RHA and this indicates that some degree of thermal insulation of the sand mix was achieved. The thermal conductivity of control sample without RHA is $1.631 \mathrm{~W} / \mathrm{m} . \mathrm{K}$ and that with $6 \mathrm{wt} \%$ RHA is 1.141 $\mathrm{W} / \mathrm{m} . \mathrm{K}$. Thus, using RHA as sand mould additive, thermal conductivity declined by $30 \%$ [8]. This can be attributed to the increased porosity as the molten metal gets in contact with the moulds having higher weight percent RHA during casting. This increased porosity reduces thermal conduction within the mould particles [8]. Researchers in [4] obtained similar results when low density alumino-silicate sand (LDASC) was used as sand additive/replacement in thin wall casting. The relationship between thermal conductivity and RHA- sand additive is downward exponential as in Equation 2 [8].

Thermal Conductivity $=1.6866 e^{-0.0626(W t \% R H A)} ; R^{2}$ $=0.9711$

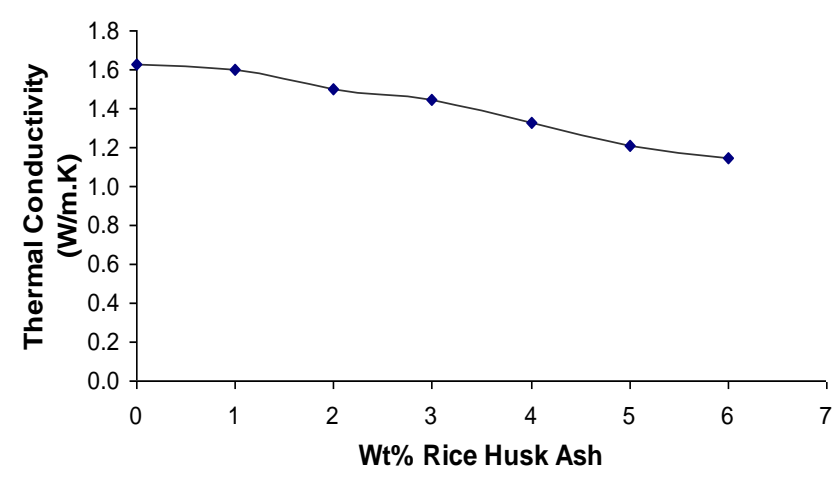

Figure 1: Thermal Conductivity of RHA-sand mould mix [8] 
Table 5: Spectrometric analysis of TWDI samples

\begin{tabular}{lllllllll}
\hline Element & Fe & C & Si & Mn & S & P & Mg & CE \\
\hline Composition (wt. \%) & 93.757 & 3.550 & 2.390 & 0.230 & 0.008 & 0.017 & 0.048 & 4.350 \\
\hline
\end{tabular}

3.2 Effect on Nodularity, Nodule Count and Matrix type (Microstructure) of Sand - RHA TWDI Cast Samples

The optical microscope, scanning electron microscope (SEM) and energy dispersive spectroscopy were used for microstructural characterization. Microstructure of $4 \mathrm{~mm}$ cast TWDI samples was greatly enhanced with RHA addition to silica mould sand. Good nodule characteristics namely, shape, size and number were observed in the optical micrographs of cast samples using RHA addition to mould sand. This promoted good nodularity rating and high nodule count. However, the SEM micrographs revealed the presence of carbide precipitates in RH, RH1 and RH3 (Plates 1c, 2c and 4c). These precipitates were plate-like in shape and the EDS analysis of samples cast using RH1 and RH3 mix (Plates 8 and 9) showed iron and carbon suggesting cementite $\left(\mathrm{Fe}_{3} \mathrm{C}\right)$. These carbide precipitates were very visible in SEM micrographs than its optical counterpart, this phase resulted from faster cooling of samples as the thermal conductivity of mould media is higher (1.631, 1,601 and $1.449 \mathrm{~W} / \mathrm{m} . \mathrm{K}$ ) respectively owing to existence of lesser pores due to smaller weight percentage of RHA additions vis-a-vis the higher porosity that exists in moulds having higher RHA content where the thermal conductivity is lower.

The reduction in thermal conductivity with RHA addition to mould sand promoted nodule count and nodularity ratings enhancement as a result of reduction in cooling rate. The researchers in [4] also observed similar results when low density alumino-silicate sand (LDASC) was used as sand additive/replacement in thin wall casting. Table 6 shows nodularity and nodule counts for $4 \mathrm{~mm}$ TWDI samples. Nodularity rating was above ninety percent $(90 \%)$ for all samples except the control and nodule counts improved $(>1000$ nodules $/ \mathrm{mm}^{2}$ ) for RH6 and RH7 (Table 6) with structure homogeneity as observed by the researchers in [11]. Matrix structure results from austenite decomposition and was influenced by chemical composition and cooling rate. Large volumes of carbide precipitates in addition to varying proportions of ferrite and pearlite were observed in the control, $\mathrm{RH}$ (Plate 1). This was also evident in RH1, RH2 and RH3 samples. The matrix consists of varying proportions of ferrite and pearlite mostly of the bull-eye structure for the carbide free samples RH4, RH5 and RH6. Pearlite structure dominates in RH4 samples, but reduces in
RH5 and RH6 samples due to increased carbon diffusion giving way to coarse ferrite matrix proportion.

Table 6: Nodularity and nodule count results for $R H A$ samples

\begin{tabular}{cccc}
\hline No & Sample & $\begin{array}{c}\text { Nodularity } \\
(\%)\end{array}$ & $\begin{array}{c}\text { Nodule Count } \\
\text { (nodules/mm2) }\end{array}$ \\
\hline 1 & RH-4 & 75 & 347 \\
2 & RH1-4 & 94 & 364 \\
3 & RH2-4 & 95 & 487 \\
4 & RH3-4 & 96 & 496 \\
5 & RH4-4 & 97 & 509 \\
6 & RH5-4 & 98 & 1344 \\
7 & RH6-4 & 97 & 1373 \\
\hline
\end{tabular}

The final microstructure consists of graphite nodules formed during eutectic solidification with matrix type made up of ferrite, pearlite or carbides formed from subsequent eutectoid reactions. These transformations depend on rate of carbon diffusion. The carbide precipitates resulted from metastable transformation and mechanical properties such as ductility and tensile strength were lowered. During solidification of RH-4 sample in the sand mould with thermal conductivity of $1.631 \mathrm{~W} / \mathrm{m} . \mathrm{K}$, heat transfer from melt occurred rapidly and this increased the undercooling. This solidification pathway prevented heterogeneous graphite nucleation process, which hindered the formation of optimum number of graphite nodules before melt solidification. Matrix types in RH-4 samples were of ferrite, pearlite and carbides (Plates $1 \mathrm{a}, 1 \mathrm{~b}$ and $1 \mathrm{c}$ ). Nodule size is $\sim 10$ $\mu \mathrm{m}$.

Addition of $1 \mathrm{wt}$. \% RHA to mould sand mix lowered thermal conductivity slightly from $1.631 \mathrm{~W} / \mathrm{m} . \mathrm{K}$ to $1.601 \mathrm{~W} / \mathrm{m} . \mathrm{K}$ and as such significant change in microstructure was not evident (Plates 2a, 2b and 2c), and is similar to those in Plates (1a, $1 \mathrm{~b}$ and 1c). Plates 5-7 show carbide free structure for RH4, RH5 and RH6 samples. Plates $(5 a, 5 b$ and $5 c)$ show large volume of pearlite, nodule size is of 5- $15 \mu \mathrm{m}$. However, for Plates (6a, 6b, 6c. 7a, 7b and 7c), larger volume of ferrite phase was observed attributed to depletion of carbon in melt for eutectoid reaction as most of the carbon nucleated as graphite during eutectic solidification. Nodule size was also between $5-15 \mu \mathrm{m}$. 

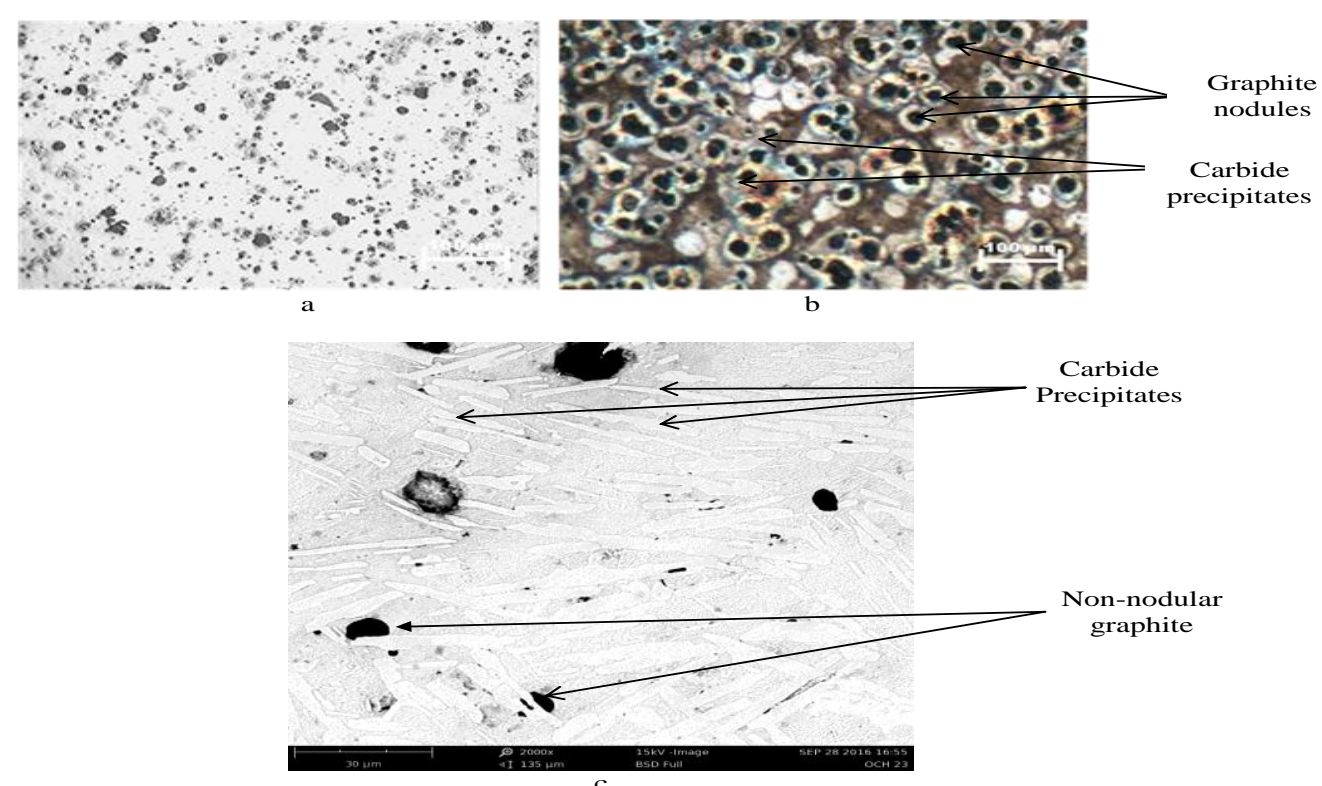

Plate 1: RH- 4 mm Micrograph (a) Optical unetched (b) optical etched (c) etched SEM
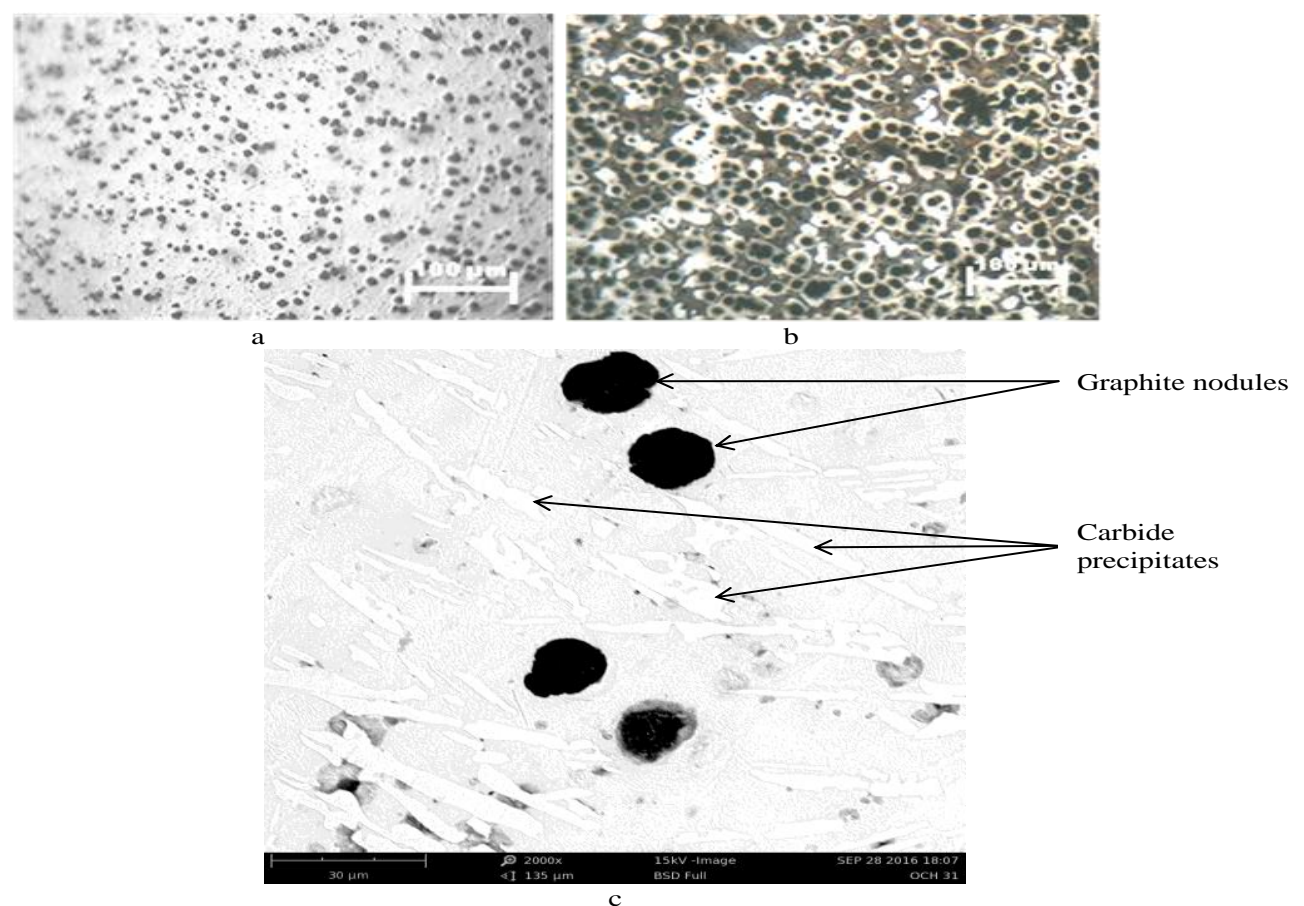

Plate 2: RH1- 4 mm Micrograph (a) unetched Optical (b) etched Optical (c) etched SEM

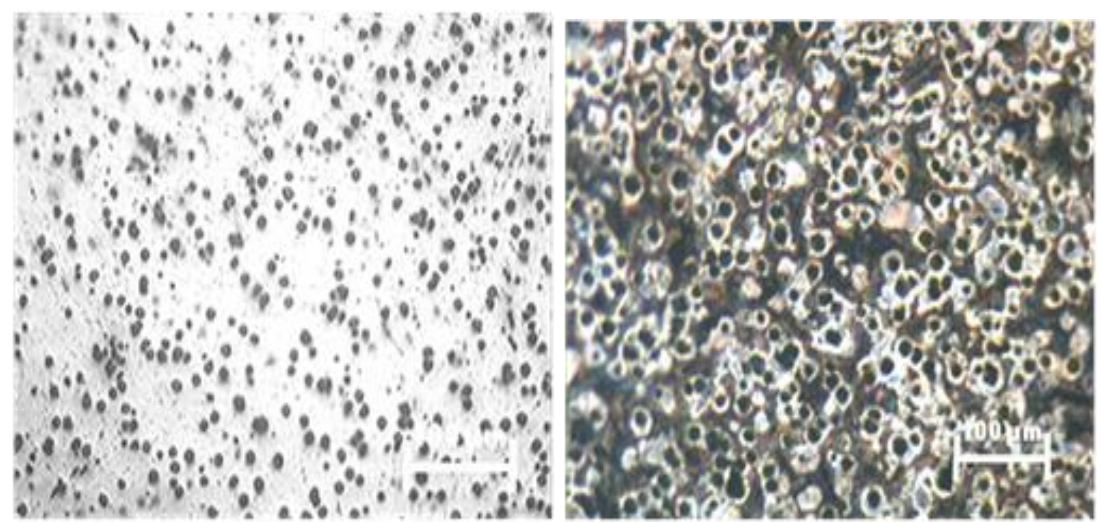

Plate 3: RH2-4mm Micrograph (a) unetched Optical (b) etched Optical 


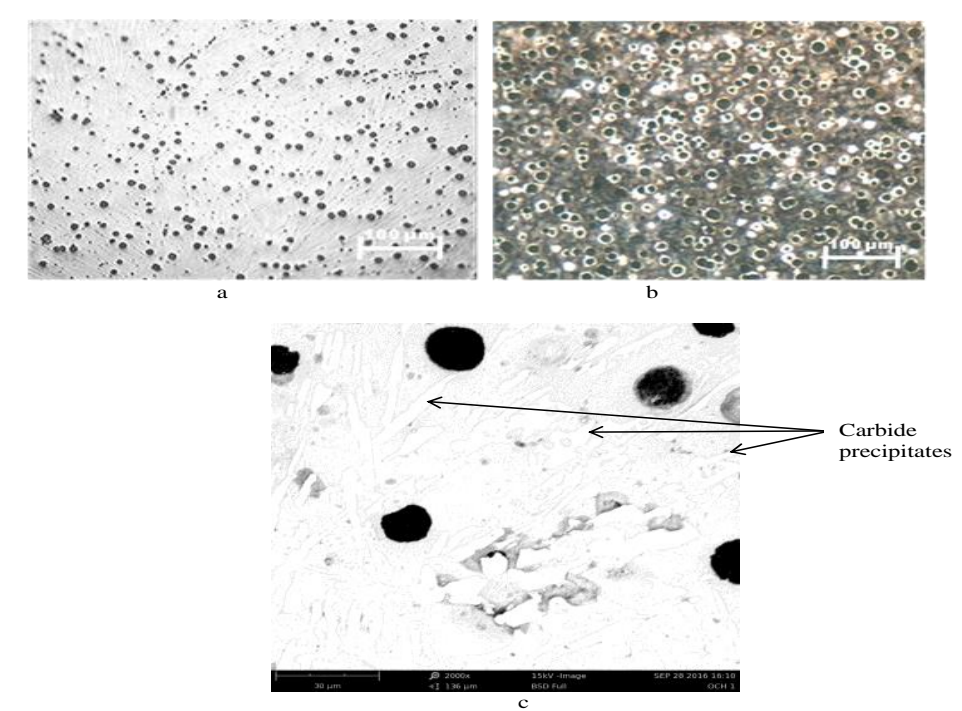

Plate 4: RH3- 4 mm Micrograph (a) unetched Optical (b) etched Optical (c) etched SEM
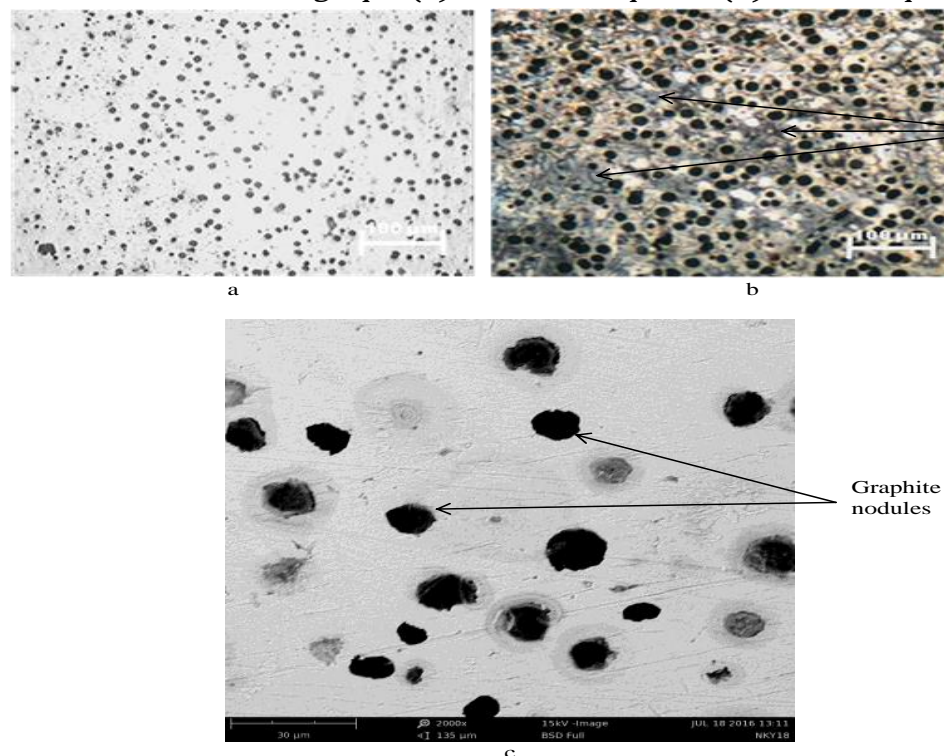

Plate 5: RH4- 4 mm Micrograph (a) unetched Optical (b) etched Optical (c) etched SEM

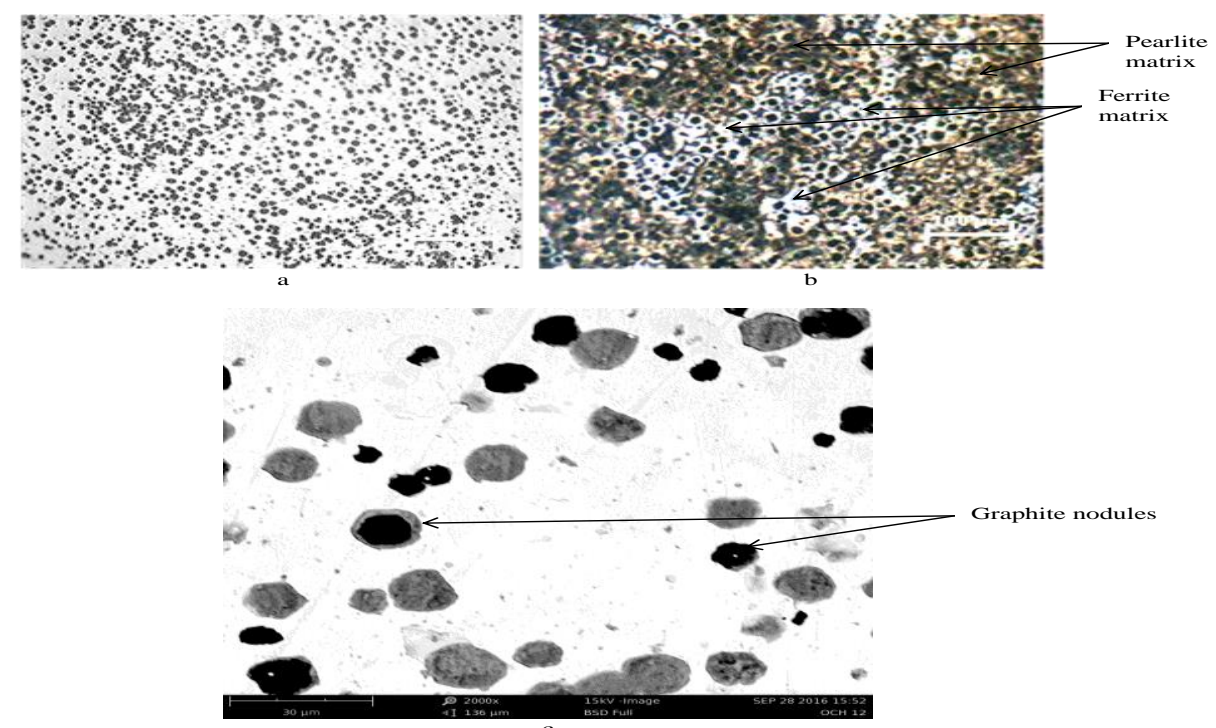

Plate 6: RH5- 4 mm Micrograph (a) unetched Optical (b) etched Optical (c) etched SEM 


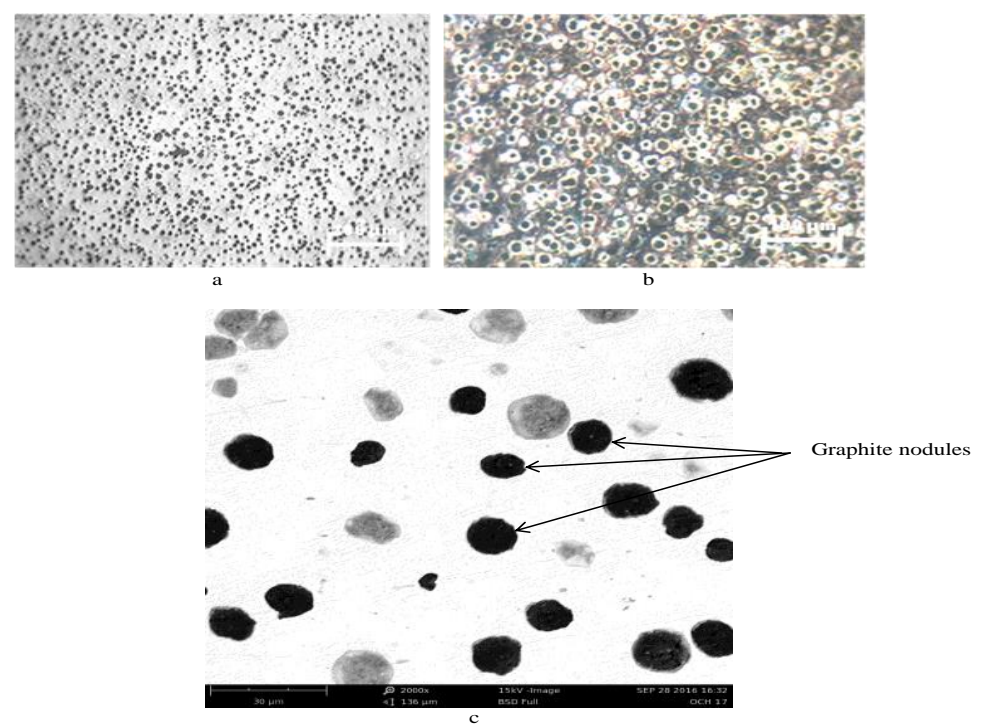

Plate 7: RH6- 4 mm Micrograph (a) unetched Optical (b) etched Optical (c) etched SEM

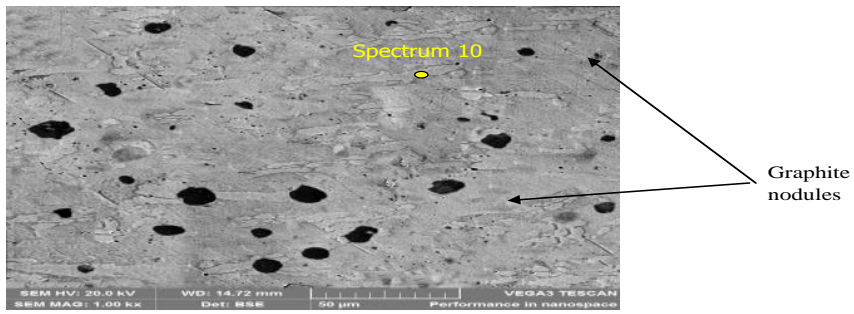

(a)

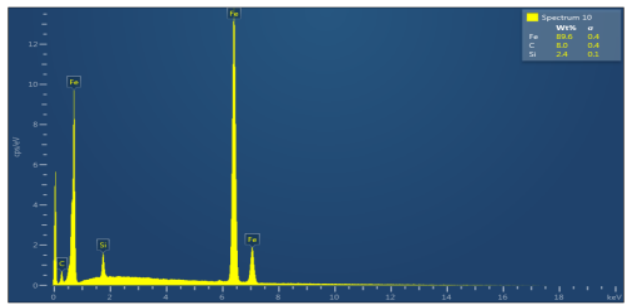

(b)

Plate 8: RH1- 4 mm Micrograph (a) SEM analysis (b) Corresponding spot EDS analysis.

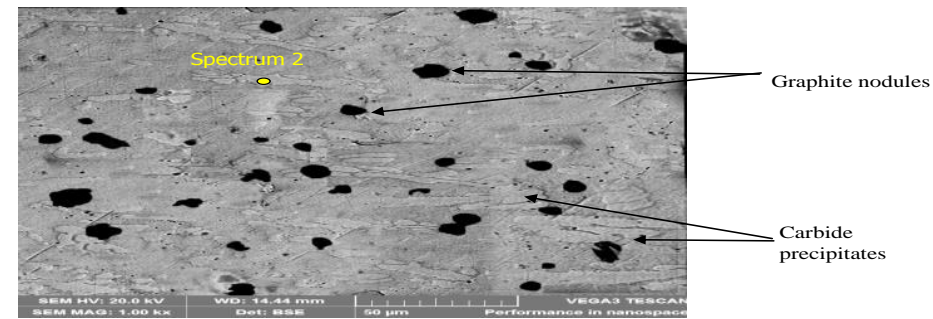

(a)

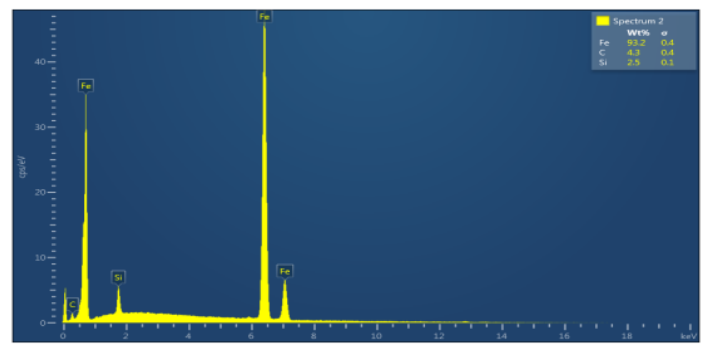

(b)

Plate 9: RH3- 4 mm Micrograph (a) SEM analysis (b) Corresponding spot EDS analysis. 


\section{3: Hardness Analysis of Sand - RHA TWDI Cast Samples}

The variation of brinell hardness number (BHN) of 4 mm TWDI samples produced from mould sand-RHA mix is shown in Figure 2. The hardness showed a linear relationship as in Equations 3 with wt. \% RHA and decrease as wt. \% RHA increases in the sand mix. This pattern agrees with the investigation conducted in [2], as cooling rate affects the maximum degree of undercooling at the beginning of graphite eutectic solidification and consequently, the structure of iron (the number of graphite nodules, metal matrix). The BHN values of 133,129 and 122 for the samples that showed carbide free matrix namely RH4, RH5 and RH6 respectively, resulted from large volume fraction of pearlite phase observed in RH4 [11] and [12]. These dropped for 5 and 6 wt. \% RHA where increased volume fraction of ferrite phase was observed. Increased volume of ferrite phase occurred owing to the presence of more sites available for heterogeneous nucleation of graphite nodule at reduced undercooling. This resulted to higher nodule counts $(>1000$ nodules $/ \mathrm{mm}^{2}$ ). The control sample RH corresponds to the highest BHN (172) attributed to large volumes of carbide precipitates (Plate 1) followed by RH1 sample (BHN 161) (Plate 2).

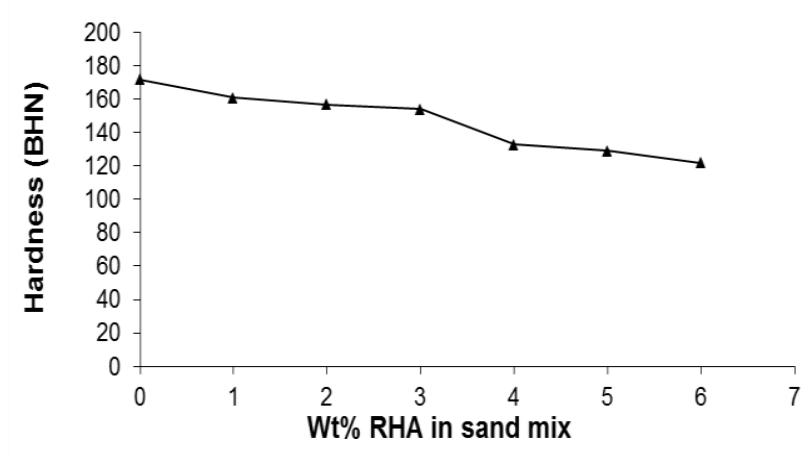

Figure 2: Variation of BHN of TWDI samples with Weight \% RHA

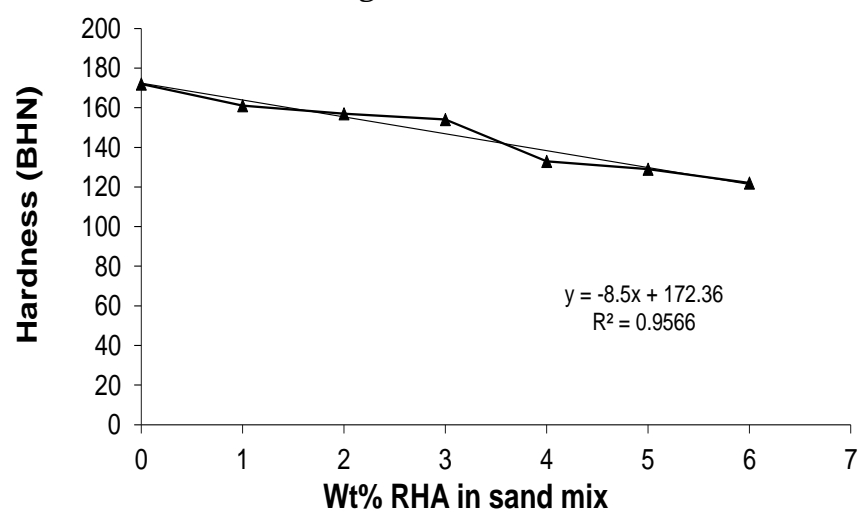

Figure 3: Regression plot for variation of BHN of TWDI samples with Weight \% RHA
Regression analysis showing the relationship of wt. \% RHA in sand mould on BHN of $4 \mathrm{~mm}$ TWDI samples as shown in Figure 3 follows a linear relationship governed by Equations 3 .

$$
\begin{array}{r}
B H N=-8.5(\text { RHA Wt. } \%)+172.36 ; \\
R^{2}=0.9566
\end{array}
$$

\subsection{Tensile Test}

The tensile responses of the $4 \mathrm{~mm}$ TWDI samples are shown in Figure 4. RHA addition improves UTS in the cast samples. The control samples cast without RHA addition to mould sand gave lowest UTS of $389 \mathrm{MPa}$. The highest UTS of 596, 573 and $567 \mathrm{MPa}$ occurred at 4, 5 and 6 wt. \% RHA additions. The highest of $596 \mathrm{MPa}$ corresponds with the highest BHN for samples, which showed carbide free microstructure. The highest UTS can be attributed to the large volume fraction of pearlite phase in matrix as observed in Plate $5 b$. Researchers in $[11,12]$ observed similar trend. The percent elongation was highest at 4-6 wt. \% RHA in mould sand. The highest value (6.1) was observed in 4 mm thick samples at 6 wt. \% RHA (Figure 5). This is attributable to increased ferrite volume as cooling rate reduced with 4 - 6 wt. \% RHA additions in sand mould and this favours stable transformation products. This finding agrees with researchers in [12] where pearlitic content of as-cast DI influences its nodule count. Increasing nodule count decreases both the pearlite content and tensile strength while it improves percent elongation.

From regression analysis in Figure 6, a quadratic relationship exist between UTS and wt. \% RHA in sand mould of TWDI samples as in Equation 4

$$
\text { UTS }=-3.1679(\text { RHA Wt. } \%)^{2}+52.389(\text { RHAWt. \%) }
$$$$
+375.83 ; \quad R^{2}=0.9477
$$

Regression analysis (Figure 7) showing the relationship of wt. \% RHA in sand mould on percent elongation of TWDI samples follow a linear relationship governed by Equations 5 .

$$
\% \text { Elong. }=0.1886(\text { RHA Wt. } \%)+4.2619 ; \quad R^{2}
$$

$$
=0.9826
$$

The sand-RHA mix impacted positively on the microstructures and mechanical properties of $4 \mathrm{~mm}$ TWDIs cast using the mix as mould medium. This is attributed to the ability of the mix to lower thermal conductivity (Figure 1). The controlled heat transfer with less degree of undercooling during the eutectic solidification allowed for sufficient time for active nucleation sites to precipitate stable transformation products of graphite structures instead of the metastable carbide precipitates. 


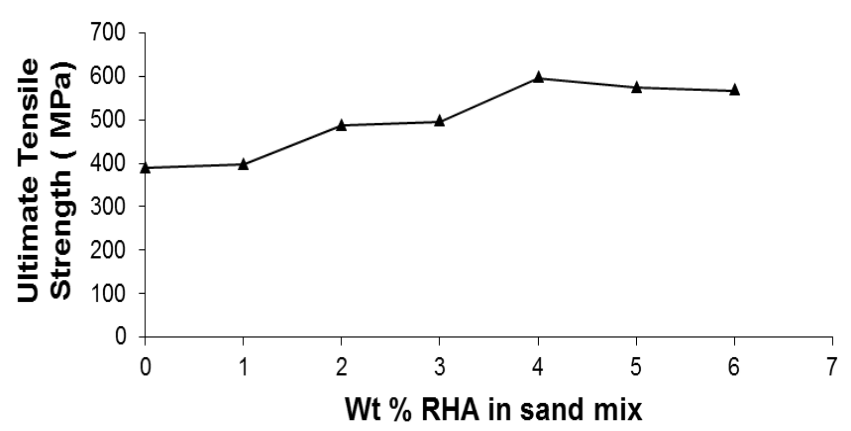

Figure 4: Variation of UTS of TWDI samples with Weight \% RHA

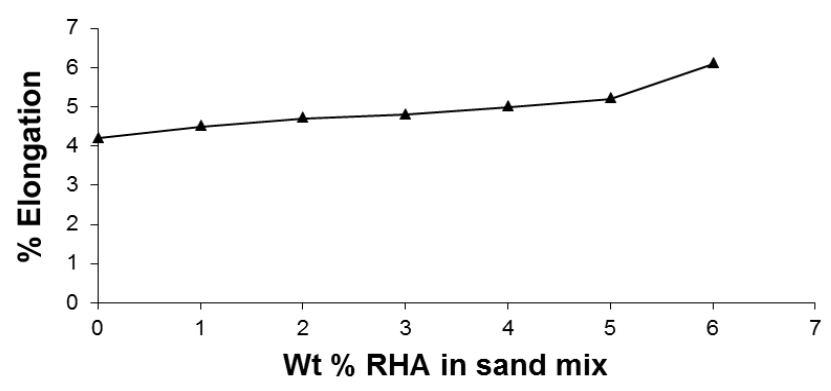

Figure 5: Variation of Percent elongation of TWDI samples with Weight \% RHA

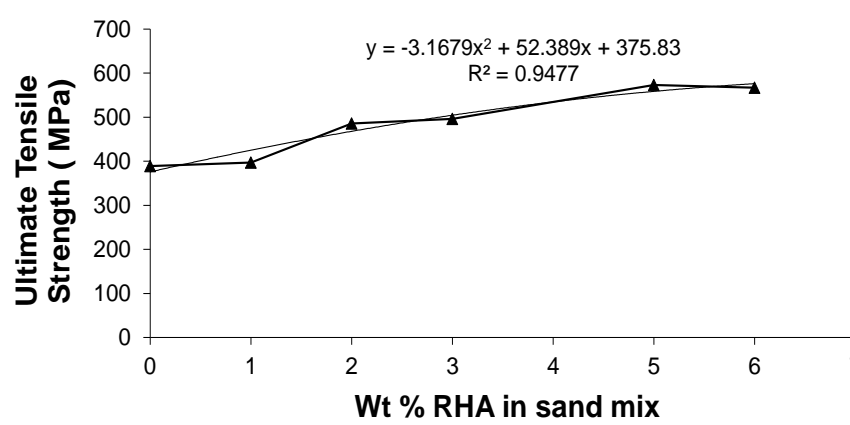

Figure 6: Regression plot for variation of UTS of TWDI samples with Weight \% RHA

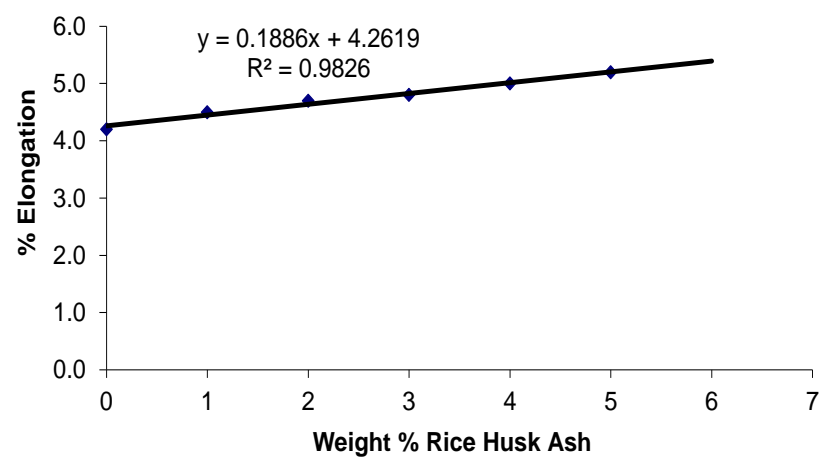

Figure 7: Regression plot for variation of percent elongation of TWDI samples with Weight \% RHA
The matrix microstructure in DI was the result of austenite decomposition. The as-cast microstructure is directly influenced by alloy content and cooling rate [12]. The cooling rate is affected by the section thickness and rate of heat removal and this in turn depends on mould geometry, mould material, treatment and pouring temperature. Thus, the mechanical properties of TWDI are influenced by graphite shape characteristics and matrix type. BHN values showed a downward trend for all samples cast using the different sand mixes and improvement in UTS was observed up to 4 wt. \% RHA in sand mould before slight drop at 5 and 6 wt. \% RHA mould additions. This drop was due to increased graphite segregation, which resulted from increased solidification time and this favours more active nuclei for graphite nodule formation vis-a-vis the reduction of solidification time for moulds of higher thermal conductivity. This leads to increased nodule count, better structure homogeneity [11], increased volume of ferrite phase and percent elongation (better ductility) but a slight decline in UTS and BHN for 5 and 6 wt. \% RHA sand mould samples. At $6 \mathrm{wt}$ \% RHA addition, the properties meet mechanical property standard specification of ASTM Spec. No A536-80 (80-50-06) for automotive application.

\section{CONCLUSION}

This study has shown that the addition of RHA to silica moulding sand has significantly reduced thermal conductivity of the resulting mould sand mix. This favoured reduction of degree of undercooling, which allows sufficient time for formation of potent nuclei for graphite nodule formation and thereby impeding carbide precipitation.

This study has also shown that it is possible to obtain carbide free, good nodules and nodule count in TWDI castings through modification of the thermal properties of mould sand.

The results show that RHA significantly reduced the thermal conductivity of the mould sand from 1.631$1.141 \mathrm{~W} / \mathrm{m}$. K. Samples cast in mould sand-RHA mix, show good nodularity ratings ( $>90 \%)$, improved nodule count (400-1300 nodules $/ \mathrm{mm}^{2}$ ) with high tensile strengths and ductility.

\section{ACKNOWLEDGMENT}

The authors gratefully thank the Management and Staff of Nigerian Foundries Ltd, Lagos and those of the Foundry shop of Federal Institute of Industrial Research (FIIRO), Oshodi, Lagos, Nigeria for their assistance in the use of their facilities. The contributions of Staff of Metallurgical Laboratory of the 
Department of Metallurgical and Materials Engineering, University of Lagos are also recognized.

\section{REFERENCES}

[1] Fraś, E., Górny, M. and Kapturkiewicz, W. “Thin Wall Ductile Iron Castings: Technological Aspects", Achives of Foundry Engineering, Vol. 13, Number 1, pp 23-28, 2013.

[2] Gorny, M. and Tyrala, E. "Effect of Cooling Rate on Microstructure and Mechanical Properties of Thin Wall Ductile Iron Castings", Journal of Materials Engineering and Performance, Vol. 22, Number 1, pp 300-305, 2013.

[3] Brandes, E. A. and Brook, G. B. Smithells Metal Reference Book, Butterworth and Heinemann, Oxford 1992.

[4] Showman, R. E and Afterheide, R. C, "A Process for Thin Wall Castings", AFS Transactions, Number 111, pp 567-578, 2003.

[5] Rihan, Y. "Numerical Study on the Effect of Solidification Parameters during the Continuous Casting of Al-Si Alloys", The Online Journal on Mathematics and Statistics, Vol. 1, Number 1, 2010.

[6] Schmidt, D. Solid Cast, Effective casting simulation, Solidification Time. Finite Solutions Incorporated.. Version 8.0.93. 2010.
[7] Gorny, M. "Temperature Drop in Liquid Iron in Thin Wall Channels during Mould Filling", Achieves of Foundry Engineering, Vol. 9, Number 1, pp 137-142, 2009.

[8] Ochulor, E. F., Amuda, M.O. H., Adeosun, S. O. and Balogun, S. A. "Effect of Aluminum Dross and Rice Husk Ash on Thermal and Moulding Properties of Silica Sand", Nigerian Journal of Technology, Vol. 36, Number 3, pp 794-800, 2017.

[9] Ochulor, E. F., Amuda, M.O.H., Adeosun, S. O. and Balogun, S. A. "Mechanical Properties of Thin Wall Ductile Iron Cast in Moulding Sand/ Aluminium Dross Mix, The West Indian Journal of Engineering, Vol. 39, Number 1, pp 17-24, 2016.

[10] Stefanescu, D. M., Dix, L. P., Ruxanda, R. E., Corbitt-Coburn, C. and Piwonka, T. S. "Tensile Properties of Thin Wall Ductile Iron", AFS Transactions, Vol. 110, pp 1149-1162, 2002.

[11] Labrecque, C., Gagné, M. and Javaid, A. "Optimizing the Mechanical Properties of ThinWall Ductile Iron Castings", AFS Transactions, Vol. 116, Number 5, pp 1-10, 2005.

[12] Sangame, B. B. and Shinde, V. D. "The Effect of Inoculation on Microstructure and Mechanical Properties of Ductile Iron". IOSR Journal of Mechanical and Civil Engineering, Vol. 5, Number 6, pp. 17-23, 2013. 